\title{
AVALIAÇÃO DE ÓLEOS DE SOJA COM DIFERENTES ORIGENS NA PRODUÇÃOO DO BIODIESEL VIA ROTA METÍLICA
}

\author{
M. R. WOLF ${ }^{1}$, I. S. T. PERASSI ${ }^{1}$, N. ASSIS ${ }^{1}$ e F. A. V. PEREIRA ${ }^{1}$ \\ ${ }^{1}$ Pontifícia Universidade Católica do Paraná, Departamento de Engenharia Química (Escola \\ Politécnica) \\ E-mail para contato: meli.rwolf@gmail.com
}

\begin{abstract}
RESUMO - Na busca por combustíveis alternativos com o propósito de minimizar o consumo de derivados de petróleo devido à alta emissão de gases poluentes, o biodiesel tem-se apresentado como uma alternativa acessível. Produzido a partir da transesterificação de óleos e gorduras na presença de álcool de cadeia curta, tem características que podem interferir no desempenho dos motores de combustão interna. Neste estudo objetivou-se realizar e analisar a produção de biodiesel via rota metílica a partir de óleo de soja virgem e residual (usado), na presença de hidróxido de sódio como catalisador, utilizando um planejamento experimental na otimização. Comparando o produto obtido oriundo de cada matéria prima utilizada, avaliou-se suas características com intenção de obter um produto viável economicamente e atender aos padrões de qualidade para sua utilização no Brasil. Após testes e aperfeiçoamentos no procedimento, obteve-se elevado rendimento $(97,53 \%)$ e valores satisfatórios para as propriedades físico-químicas do biocombustível.
\end{abstract}

\section{INTRODUÇÃO}

Os derivados de combustíveis fósseis compõem as principais fontes energéticas no Brasil e no mundo, porém, se explorados de forma e quantidade inadequadas, podem se esgotar (RAMOS et al., 2011). Segundo Lôbo et al. (2009), com o propósito de atender a demanda energética mundial e devido à grande poluição causada pela queima de combustíveis fósseis, as pesquisas a respeito de fontes de energia alternativas estão em constante crescimento. Como alternativa ao diesel mineral, pode-se usar o biodiesel - um biocombustível atóxico, oriundo de fontes renováveis e que emite quantidades de gases poluentes inferiores aos derivados de petróleo nos processos de combustão. Além disso, proporciona menores desgastes nos motores de combustão interna e baixo risco de explosão, podendo ser utilizado em forma de mistura com o mesmo sem necessitar alterações no motor para a sua utilização (LÔBO et al, 2009; VILLADIEGO et al, 2015).

O biodiesel é uma mistura de ésteres monoalquílicos obtidos principalmente da transesterificação dos triglicerídeos de gorduras e óleos com álcoois de cadeia curta como o metanol e o etanol, na presença de catalisador básico. De acordo com Lôbo et al. (2009), o metanol, álcool muito empregado para transesterificação em escala comercial pelo alto rendimento e baixo custo, é altamente reativo, o que resulta em menor temperatura e tempo de reação, sendo assim, mais rápido e fácil do que o etanol, apesar deste último ser menos tóxico e renovável, produzido a partir de biomassa. 


\section{Congresso Brasileiro de Engenharia Química \\ em Iniciação Científica \\ UFSCar - São Carlos - SP \\ 16 a 19 de Julho de 2017}

Em conformidade com Villadiego et al. (2015), para resolver o problema de espaço para plantação e quantidade de água necessária para as oleaginosas, cita-se a possibilidade da utilização de óleos residuais, ou seja, óleos que já foram utilizados para frituras em domicílios e restaurantes, gerando ainda um destino para os mesmos e evitando a poluição de lagos e rios.

Conforme Barradas Filho (2015), Dapieve (2015) e Ramos et al. (2011), o biodiesel vem ganhando vários programas de incentivo à produção e uso nas últimas décadas, sendo que no Brasil as tentativas de implementação de biodiesel foram introduzidas na década de 1970. A produção de biodiesel a partir de óleo de soja é predominante no país, seguida por gordura bovina.

Desta forma, o presente estudo objetivou obter biodiesel a partir de óleo de soja residual e virgem via rota metílica, realizando a comparação de características e propriedades físicoquímicas entre os óleos utilizados no processo e seus produtos. Visando melhoria nos resultados, um procedimento experimental de otimização foi elaborado variando o tempo de reação e a proporção entre óleo, metanol e catalisador, pretendendo aumentar o rendimento da reação e obter-se um produto dentro dos padrões requeridos e que possibilite bom funcionamento do motor.

\section{MATERIAIS E MÉTODOS}

\subsection{Produção de Biodiesel}

Primeiramente, realizou-se uma filtração a vácuo no óleo residual para remover impurezas oriundas de utilizações anteriores e armazenou-o em frasco fechado, sendo apenas esta a diferença entre os processos a partir de óleo virgem e residual.

Mensurou-se $250 \mathrm{~mL}$ de metanol com auxílio de uma proveta e transferiu-o para um béquer de $500 \mathrm{~mL}$, juntamente com 5,0 g de hidróxido de sódio P.A.. Os reagentes foram misturados com auxílio de agitador mecânico até completa dissolução do catalisador. Posteriormente, $500 \mathrm{~mL}$ de óleo de soja foram aquecidos até $45{ }^{\circ} \mathrm{C}$ e adicionou-se a mistura de metanol e catalisador. Homogeneizou-se a mistura com o agitador magnético durante 5 minutos e posteriormente, mais 5 minutos com auxílio de bastão de vidro. A mistura foi colocada em um funil de decantação por aproximadamente 24 horas, até completa separação de fases. A glicerina, de cor escura, depositada no fundo do funil de separação foi retirada e armazenada em frasco âmbar.

Subsequentemente, realizou-se uma lavagem no biodiesel, constituída pelo mesmo volume de água á $90^{\circ} \mathrm{C}$ em relação ao biodiesel colocada novamente no funil de separação, seguida de leve agitação e decantação até completa separação da água. Após, a água contendo o excesso de metanol foi retirada e realizou-se uma filtração a vácuo no biodiesel. Em seguida, verificou-se a massa e o volume do biodiesel formado e armazenou-o em frasco âmbar.

\subsection{Otimizações}

Com o propósito de otimização dos resultados obtidos com o procedimento experimental acima descrito, realizou-se um planejamento fatorial $2^{3}$, variando o tempo de reação, a massa do catalisador e a proporção metanol:óleo utilizada, parâmetros com grande influência no rendimento do produto, e permanecendo constante o volume de óleo $(500 \mathrm{~mL})$ e a temperatura de reação. A tabela 1 apresenta os ensaios realizados. 


\section{Congresso Brasileiro de Engenharia Química \\ em Iniciação Científica \\ UFSCar - São Carlos - SP \\ 16 a 19 de Julho de 2017}

Tabela 1 - Ensaios realizados no planejamento experimental

\begin{tabular}{c|c|c|c}
\hline Ensaio & $\begin{array}{c}\text { Razão volumétrica } \\
\text { óleo:metanol }\end{array}$ & $\begin{array}{c}\text { Massa de } \\
\text { catalisador }(\mathrm{g})\end{array}$ & $\begin{array}{c}\text { Tempo de reação } \\
(\mathrm{min})\end{array}$ \\
\hline 1 & $4: 1$ & 2,5 & 6 \\
\hline 2 & $1: 1$ & 7,5 & 20 \\
\hline 3 & $4: 1$ & 2,5 & 20 \\
\hline 4 & $4: 1$ & 7,5 & 6 \\
\hline 5 & $1: 1$ & 2,5 & 6 \\
\hline 6 & $1: 1$ & 7,5 & 20 \\
\hline 7 & $4: 1$ & 7,5 & 6 \\
\hline 8 & $1: 1$ & 2,5 & 10 \\
\hline 9 & $2: 1$ & 5,0 & \\
\hline
\end{tabular}

Fonte: as autoras, 2017.

\subsection{Caracterização do Biodiesel}

Massa específica: Determinou-se à aproximadamente $20^{\circ} \mathrm{C}$ com auxílio de um densímetro com escala 0,8 a $0,9 \mathrm{~g} / \mathrm{mL}$. Ensaios realizados em triplicata por amostra.

Índice de acidez: Determinou-se o índice de acidez conforme a norma ASTM D2500-05 descrita por Chendynski et al (2014).

Ponto de névoa: Verificado de acordo com norma ASTM D2500, citada por Dapieve (2015).

Teor de umidade: $5 \mathrm{~g}$ da amostra foram pesadas, colocadas em cadinho já dessecado com o auxílio da pipeta e levados à estufa a $105{ }^{\circ} \mathrm{C}$. Após 24 horas, retirou-se a amostra da estufa e pesou-se. O teor de umidade foi calculado através da equação 1, descrita por Oliveira et al. (2015), onde TU indica o teor de umidade, vf o volume final e vi o volume inicial de amostra.

$$
T U=\frac{v_{f}-v_{i}}{v_{i}} 100
$$

\section{RESULTADOS E DISCUSSÕES}

\subsection{Produção de Biodiesel e Otimizações}

O rendimento da reação de transesterificação foi calculado fundamentando-se na massa de óleo de soja inicial e na massa do biodiesel obtida ao final da reação, segundo a equação 2.

$$
R e=\frac{\text { massa de biodiesel }}{\text { massa de óleo }} 100
$$

Segundo Santos (2015), o rendimento da reação é um fator bastante importante economicamente e pode ser afetado com a mudança no tempo de reação, na temperatura e também pelas condições em que a matéria prima se encontra, como índice de acidez e umidade do óleo. A tabela 2 apresenta o rendimento das reações de transesterificação no ponto central.

A alta pureza dos reagentes e matéria prima explica o alto rendimento obtido. Pode-se observar uma diferença no rendimento do biodiesel a partir do óleo virgem e do óleo residual, a 


\section{Congresso Brasileiro de Engenharia Química \\ em Iniciação Científica \\ UFSCar - São Carlos - SP \\ 16 a 19 de Julho de 2017}

CONGRESSO BRASILEIRO DE ENGENHARIA

qual pode-se fundamentar no fato de que, por mais que o óleo residual tenha passado apenas por um processo de cocção e seja realizada uma filtração à vácuo anteriormente a reação, o mesmo pode conter pequenas impurezas, maior umidade e acidez mais elevada (SANTOS, 2015). A figura 1 retrata o biodiesel obtido a partir da matéria prima diferenciada.

Tabela 2 - Rendimentos das reações de transesterificação

\begin{tabular}{c|cc}
\hline Óleo & Virgem & Residual \\
\hline $\boldsymbol{R e}(\%)$ & $97,53 \pm 0,02$ & $94,13 \pm 0,52$ \\
\hline
\end{tabular}

Fonte: as autoras, 2017.

Figura 1 - Biodiesel a partir de óleo virgem e óleo residual, respectivamente.

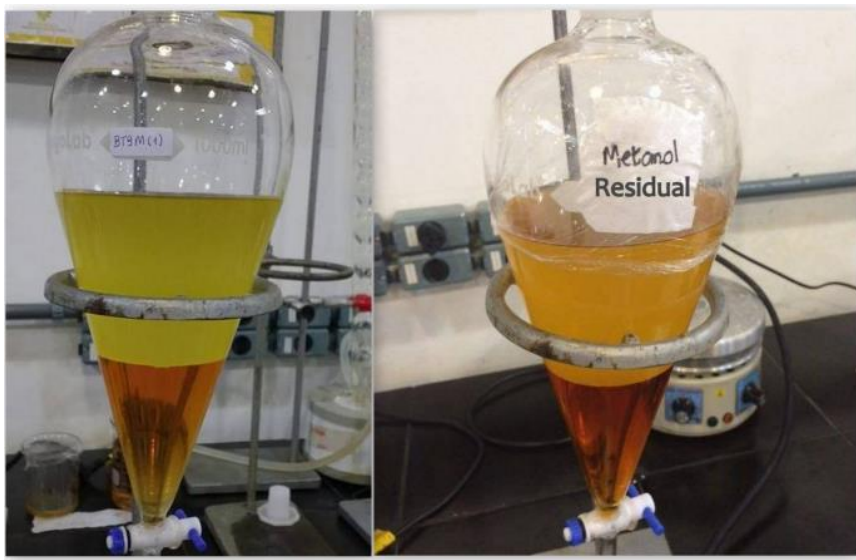

Fonte: as autoras, 2017.

Pode-se observar a diferença na coloração do biodiesel, devido à maior acidez e impurezas do óleo de fritura.

\subsection{Otimizações}

A tabela 3 apresenta o rendimento das reações para o planejamento experimental realizado. Os ensaios 2, 5, 6 e 8 apresentaram rendimento inferior aos demais. Pode-se notar que a reação para esses ensaios foi realizada com razão volumétrica 1:1 (óleo:metanol), ou seja, com maior volume de metanol. Nestes ensaios, houve maior quantidade de sabão e de emulsões formadas, dificultando a separação do produto final e ocasionando grandes perdas, principalmente na lavagem do produto final (MOREIRA, 2009).

Tabela 3 - Rendimento das Reações de Transesterificação

\begin{tabular}{c|ccccccccc}
\hline Ensaio & $\mathbf{1}$ & $\mathbf{2}$ & $\mathbf{3}$ & $\mathbf{4}$ & $\mathbf{5}$ & $\mathbf{6}$ & $\mathbf{7}$ & $\mathbf{8}$ & $\mathbf{9}$ \\
\hline $\begin{array}{c}\text { Rendimento } \\
(\%)\end{array}$ & 95,68 & 62,19 & 95,69 & 89,34 & 56,78 & 55,84 & 90,43 & 86,49 & 97,53 \\
\hline
\end{tabular}

Fonte: o autor, 2016.

Observa-se na figura 2 que a menor massa de catalisador e a menor razão volumétrica óleo:metanol resultaram em maior rendimento. Portanto, os ensaios que obtiveram os melhores rendimentos foram BT1, BT3 e BT9. Através desses ensaios pode-se observar ainda que o tempo não teve grande influência no rendimento da reação, pois houve pouca variação do volume de biodiesel obtido quando compara-se os ensaios 1 e 3, por exemplo. 


\section{Congresso Brasileiro de Engenharia Química \\ em Iniciação Científica \\ UFSCar - São Carlos - SP \\ 16 a 19 de Julho de 2017}

Figura 2 - Contorno da resposta do rendimento com tempo de reação constante

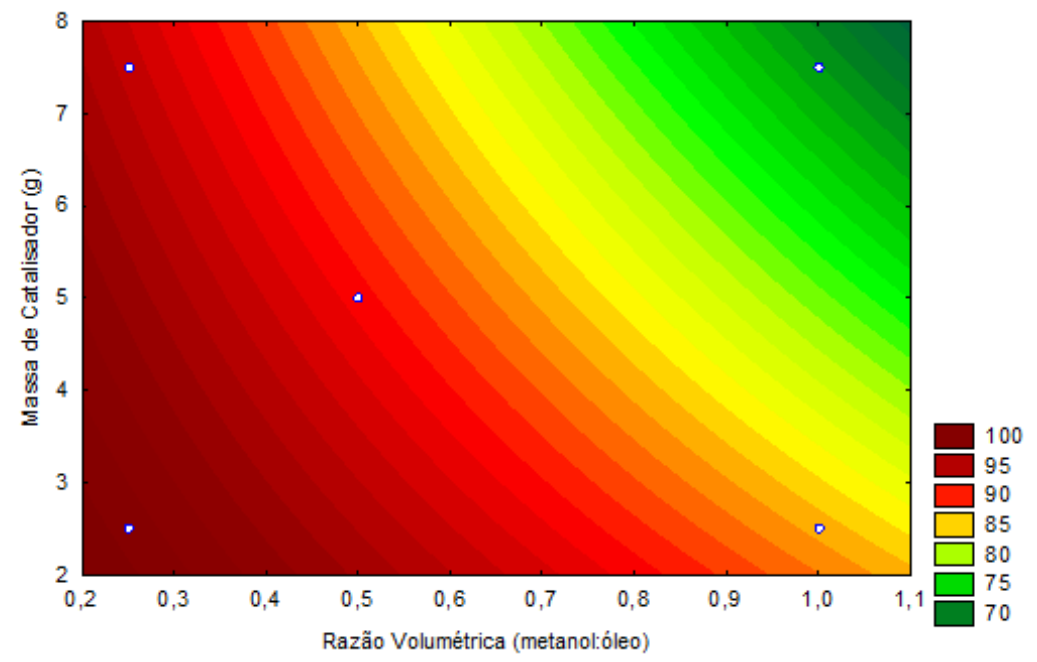

\subsection{Caracterização do Biodiesel}

As características analisadas são evidenciadas na tabela 4, para os principais ensaios realizados.

Tabela 4 - Propriedades físico-químicas dos biodieseis obtidos.

\begin{tabular}{c|cccc}
\hline Biodiesel & $\rho\left(\mathrm{kg} / \mathrm{m}^{3}\right)$ & $\begin{array}{c}\text { IA (mg KOH/} \\
\text { g óleo })\end{array}$ & $\begin{array}{c}\text { Ponto de } \\
\text { Névoa }\left({ }^{\circ} \mathrm{C}\right)\end{array}$ & $T U(\%)$ \\
\hline Residual & $877,4 \pm 2,30$ & $0,670 \pm 0,222$ & $0 \pm 1$ & $0,1282 \pm 0,077$ \\
1 & $879,4 \pm 9,71$ & $0,322 \pm 0,064$ & $0 \pm 1$ & $0,2291 \pm 0,202$ \\
3 & $882,8 \pm 0,84$ & $0,389 \pm 0,101$ & $0 \pm 1$ & $0,2582 \pm 0,204$ \\
4 & $876,0 \pm 0,64$ & $0,276 \pm 0,001$ & $-1 \pm 1$ & $0,1393 \pm 0,068$ \\
7 & $893,3 \pm 2,59$ & $0,312 \pm 0,066$ & $0 \pm 1$ & $0,7883 \pm 0,085$ \\
9 & $881,0 \pm 1,80$ & $0,347 \pm 0,097$ & $-1 \pm 1$ & $0,1352 \pm 0,085$ \\
\hline
\end{tabular}

Fonte: A autora, 2016.

A massa específica do biodiesel influencia no funcionamento e desempenho do motor. De acordo com a norma ANP 07/2008, este parâmetro deve estar entre 850 e $900 \mathrm{~kg} / \mathrm{m}^{3}$. Todos os ensaios atenderam à essa exigência (LÔBO et al., 2009).

Ainda de acordo com esta norma, o índice de acidez reflete o grau de degradação do produto durante sua armazenagem e tem um limite máximo de $0,5 \mathrm{mg} \mathrm{KOH} / \mathrm{g}$ amostra. O biodiesel obtido a partir de óleo residual obteve leve elevação neste parâmetro, provavelmente devido à matéria prima ser mais ácida do que o óleo virgem.

Segundo Dapieve (2015), o ponto de névoa é a temperatura onde ocorre a formação dos primeiros cristais de hidrocarbonetos e tem seu valor referência em $0^{\circ} \mathrm{C}$. Sendo assim, os valores são satisfatórios pois indicam que o biodiesel obtido pode ser usado para baixas temperaturas. 


\section{Congresso Brasileiro de Engenharia Química \\ em Iniciação Científica \\ UFSCar - São Carlos - SP \\ 16 a 19 de Julho de 2017}

CONGRESSO BRASILEIRO DE ENGENHARIA

Para teor de umidade, a norma ASTM D6751 determina 0,05\% em volume de água como valor máximo (LÔBO et al, 2009). Os valores obtidos estão acima do permitido, porém pode ser explicado devido à lavagem com água realizada após a reação de transesterificação. Um processo para remoção desta umidade pode ser proposto na sequência do estudo.

\section{CONCLUSÃO}

O Brasil possui variedade e abundância quando se trata de matéria prima para produção de biocombustíveis, além do clima tropical e da vasta área geográfica, facilitando para que o biodiesel seja uma fonte propícia de energia renovável.

Nesta pesquisa, o biodiesel foi produzido por transesterificação com catálise básica a partir de óleos de soja de diferentes origens: residual e virgem. Após realização do planejamento experimental, concluiu-se que a metodologia utilizada é viável e que os ensaios 1,3 e 9 apresentaram maiores conversões em ésteres metílicos e caracterização satisfatória.

A produção de biodiesel em escala industrial é uma boa alternativa para geração de empregos, para reduzir a dependência de importação do óleo diesel e ainda apresenta grandes vantagens ambientais.

\section{REFERENCIAS}

BARRADAS FILHO, A. O.; Avaliação de matérias primas para qualidade de biodieseis pela predição de propriedades físico-químicas. Tese (Doutorado) - Programa de PósGraduação em Engenharia de Eletricidade, Universidade Federal do Maranhão. São Luis, 2015.

CHENDYNSKI, L.T. et al. Pontos de névoa e fluidez em biodiesel produzido por misturas de lipídios. Revista Brasileira de Energias Renováveis, v.3, p. 307-316, 2014.

DAPIEVE, D. R. Análise da influência da temperatura sobre propriedades físico-químicas de amostra de diesel, biodiesel e suas misturas. Dissertação- Programa de Pós-Graduação em Tec. Ambientais, Universidade Tecnológica Federal do Paraná. Medianeira, 2015.

LÔBO, I. P.; FERREIRA, S. L. C.; Biodiesel: Parâmetros de qualidade e métodos analíticos. Química Nova, v. 32, n. 6, p. 1596-1608, 2009.

OLIVEIRA, Maria Aparecida Bezerra et al. Síntese e caracterização de biodiesel de algodão e soja. Disponível em: < http://www.editorarealize.com.br/revistas/co nepetro/trabalhos/Modalidade_4datahora_08_04_2015_21_54_11_idinscrito_1120_8ffa 0c9459ba370fa993f866fcdbdf91.pdf>. Acesso em: 07 ago. 2016.

RAMOS, L. P.; SILVA, F. R.; MANGRICH, A. S.; CORDEIRO, C. S. Tecnologias de produção de biodiesel. Revista Virtual de Química, v. 3, n. 5, p. 385-405, 2011.

SANTOS, D. Q. Transesterificação de triacilglicerol de óleos de milho e soja, 2010. Tese (Doutorado) - Programa Multiinstitucional de Doutorado em Química, Universidade Federal de Goiás/Universidade Federal de Mato Grosso do Sul/Universidade Federal de Uberlândia, 2015.

VILLADIEGO, M. M.; ROA, Y. O.; BENÍTEZ, L. T.. Esterificación y transesterificacíon de aceites residuales para obtener biodiesel. Revista Luna Azul, n. 40, p. 25-34, 2015. 